\title{
Fatores associados às práticas de violência conjugal em mulheres de apenados
}

Factors associated with conjugal violence practices in convicted women Factores asociados a las prácticas de violencia conyugal en mujeres de presidiarios

Vanessa Carla Batista ${ }^{1}$ iD https://orcid.org/0000-0002-3267-3969

Sonia Silva Marcon ${ }^{1}$ io https://orcid.org/0000-0002-6607-362X

Guilherme Oliveira de Arruda ${ }^{1}$ is https://orcid.org/0000-0003-1690-4808

Elen Ferraz Teston ${ }^{1}$ id https://orcid.org/0000-0001-6835-0574

Lorenna Viccentine Coutinho Monteschio ${ }^{1}$ io https://orcid.org/0000-0002-1486-6898

Fernando José de Godoy ${ }^{1}$ io https://orcid.org/0000-0001-9722-6425

Alexandrina Aparecida Maciel Cardelli ${ }^{1}$ id https://orcid.org/0000-0002-0222-8821

Eraldo Schunk Silva ${ }^{1}$ id https://orcid.org/0000-0002-6253-5962

Como citar:

Batista VC, Marcon SS, Arruda GO, Teston EF, Monteschio LV, Godoy FJ, et al. Fatores associados às práticas de violência conjugal em mulheres de apenados. Acta Paul Enferm. 2020;33:APE20190150.

DOI

http://dx.doi.org/10.37689/actaape/2020AR01505

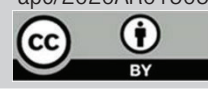

Descritores

Violência por parceiro íntimo; Saúde da mulher: Determinação de necessidades de cuidados de saúde; Violência

Keywords

Intimate partner violence; Women's health; Needs assessment; Violence

Descriptores

Violencia de pareja; Salud de la mujer; Evaluación de necessidade; Violencia

Submetido

19 de Junho de 2019

Aceito

30 de Janeiro de 2020

\section{Autor correspondente}

Vanessa Carla Batista

E-mail: vane.vcb@hotmail.com

\section{Resumo}

Objetivo: Identificar fatores associados às práticas de violência conjugal em mulheres de apenados.

Métodos: Estudo transversal realizado com mulheres que visitavam seus parceiros em uma Penitenciária do estado do Paraná. Os dados foram coletados no período de março a julho de 2018, com aplicação do Checklist de Avaliação de Risco de Violência contra Parceira Íntima. Na análise dos dados foi utilizada estatística descritiva, teste de associação de qui-quadrado e estimativas de Razão de Prevalência a partir de modelos de regressão de Poisson.

Resultados: Os fatores associados à prática de violência foram: estado civil, religião, presença de filhos e uso de substâncias químicas por parte do parceiro. Os tipos mais frequentes de violência foram: ameaças, impedimento da procura de serviços de saúde e privação de contato com terceiros.

Conclusão: Os fatores sociodemográficos influenciam a ocorrência de violência conjugal, e a detecção precoce pode ajudar no rastreamento de mulheres em risco e no estabelecimento de intervenções, pois são comportamentos passíveis de alteração.

\section{Abstract}

Objective: To identify the factors associated with conjugal violence practices in convicted women.

Methods: A cross-sectional study conducted with women who visited their partners in a prison in the state of Paraná. Data were collected from March to July 2018, using the Checklist for Assessing the Risk of Violence against Intimate Partners. In the data analysis, descriptive statistics, Chi-Square Test association and Prevalence Ratio estimates using Poisson Regression models were used.

Results: The factors associated with violence practice were: marital status, religion, presence of children and use of chemical substances by the partner. The most frequent types of violence were threats, impediment of seeking health services and deprivation of contact with third parties.

Conclusion: Sociodemographic factors influence the occurrence of conjugal violence, and early detection can help in the screening of women at risk and in the establishment of interventions, as they are behaviors that can be changed.

\section{Resumen}

Objetivo: Identificar factores asociados a las prácticas de violencia conyugal en mujeres de presidiarios.

Métodos: Estudio transversal realizado con mujeres que visitaban a sus parejas en una penitenciaría del estado de Paraná. Los datos se recolectaron en el período de marzo a julio de 2018, mediante aplicación de 
Check-list de Evaluación de Riesgo de Violencia contra la Pareja. Para analizar los datos se utilizó estadística descriptiva, prueba de relación de ji cuadrado y estimativas de razón de prevalencia a partir de modelos de regresión de Poisson.

Resultados: Los factores asociados a la práctica de violencia fueron: estado civil, religión, presencia de hijos y uso de sustancias químicas por parte del compañero. Los tipos de violencia más frecuentes fueron: amenazas, impedimento para obtener servicios de salud y privación de contacto con terceros.

Conclusión: Los factores sociodemográficos influyen en los casos de violencia conyugal y la detección temprana puede ayudar a rastrear mujeres en riesgo y a establecer intervenciones, ya que son comportamientos que pueden modificarse.

\section{Introdução}

A violência conjugal contra a mulher representa um problema de saúde pública e é um importante condicionante da saúde feminina, porque impacta negativamente na vida das vítimas e demais envolvidos. ${ }^{(1)}$ Encontra-se estreitamente ligada às desigualdades existentes nas relaçôes sociais entre homens e mulheres, construídas, naturalizadas e reproduzidas social e culturalmente nos âmbitos público e privado, em decorrência da opressão de gênero, majoritariamente o masculino sobre o feminino. ${ }^{(2)}$ Cotidianamente, inúmeras mulheres estão expostas às formas negligenciadas de violência, com episódios graves, repetitivos e com repercussão na saúde física e mental. ${ }^{(3)}$

Estima-se que uma em cada três mulheres que tiveram um parceiro já sofreram violência física e/ ou sexual em algum momento da vida. ${ }^{(4)}$ Em 2015, 4.621 mulheres foram assassinadas no Brasil, o que corresponde a uma taxa de 4,5 mortes para cada 100 mil mulheres. Destaca-se que, diante da aflição sofrida pela população feminina, cotidianamente, esses dados representam, minimamente, a carga de violência que impacta a vida das vítimas. ${ }^{(5,6)}$

Em 2016, pesquisa encomendada pelo Fórum Brasileiro de Segurança Pública apontou que 29\% das mulheres incluídas no estudo relataram ter sofrido algum tipo de violência, sendo que $11 \%$ delas fizeram denúncia em uma delegacia da mulher, e em $43 \%$ dos casos a agressão mais grave ocorreu no domicílio da vítima. ${ }^{(5)}$

As questóes que envolvem a violência conjugal são multifatoriais e de difícil solução. ${ }^{(7)}$ No que diz respeito a mulheres com parceiros apenados, estas apresentam maior predisposição por estarem mais expostas a situações de perigo e criminalidade. ${ }^{(8)}$ Além disso, geralmente encontram-se em situação de vulnerabilidade e, às vezes, chegam a adotar comportamentos de risco em prol da manutenção do relacionamento com o parceiro apenado. ${ }^{(9)}$

Ademais, o estigma e estereótipos construídos e atribuídos a essas mulheres perpetua as mais diversas expressóes de violência em seus cotidianos e as impede de expor suas necessidades e buscar apoio. ${ }^{(10)}$ Estudo realizado com 349 mulheres de apenados, nas três maiores penitenciárias do estado do Paraná, revelou que elas se submetem às açóes violentas do parceiro por medo, e algumas são obrigadas a práticas que as expóem a impactos físicos e psicológi$\cos ,{ }^{(11)}$ e também à gravidez indesejada, a Infecçóes Sexualmente Transmissíveis (IST's), a quadros de depressão, síndrome do pânico, ansiedade e distúrbios psicossomáticos. ${ }^{(12)}$

Outro fator importante é que a maioria das mulheres de apenados é oriunda de áreas carentes, possui baixa escolaridade e dificuldades de inserção no mercado de trabalho. Por essas razóes, e também pelo fato de se relacionarem com homens envolvidos com a criminalidade, essas mulheres podem ser vítimas atuais ou pregressas de violência. ${ }^{\left({ }^{8}\right)}$ Uma revisão de literatura sobre violência conjugal apontou que, embora esses estudos tenham crescido substancialmente nos últimos anos, não foram encontrados estudos voltados a essa população em especial. ${ }^{(13)}$ Frente ao exposto, questiona-se: quais os fatores associados à violência conjugal em mulheres de apenados? Assim, definiu-se como objetivo deste estudo identificar fatores associados às práticas de violência conjugal em mulheres de apenados.

\section{Métodos}

Estudo descritivo, com delineamento transversal, realizado com mulheres que aguardavam o horário de visita em uma Penitenciária Estadual localizada na região Noroeste do Estado do Paraná, destinada a 
indivíduos do sexo masculino. A Penitenciária possui 60 celas com capacidade para seis presos cada, perfazendo um total de 360 vagas. Entretanto, por ocasiāo do estudo, 452 indivíduos cumpriam pena em regime fechado, sendo que destes, 325 tinham cadastro ativo para o recebimento de visita íntima.

Nessa instituição, as visitas são realizadas três vezes por semana (sextas-feiras, sábados e domingos), em dois horários (das 8:00 horas ao meio-dia e das 13:30 às 17:00 horas). Conforme o relato das participantes, elas chegam para as visitas a partir das 4:00 horas da manhá, sendo que algumas dormem no local, com o intuito de serem as primeiras a entrar, por exigência do companheiro. Cada visitante pode ficar até quatro horas com o apenado. Em todos os dias de visita, a instituição disponibiliza 10 quartos para visita íntima, mas o apenado só pode fazer uso desta prerrogativa uma vez por semana. Os quartos são utilizados concomitantemente, sendo que cada casal pode usufruir de ambiente privativo por $30 \mathrm{a}$ 40 minutos.

Os dados foram coletados no período de março a julho de 2018, ocasião em que as participantes do estudo foram informadas que se tratava de uma pesquisa sobre violência conjugal. Os critérios de inclusão adotados foram: idade igual ou superior a 18 anos e estar aguardando visita ao companheiro. Ressalta-se que nenhum critério de exclusão foi adotado, pois se pretendia abordar o maior número possível de mulheres. Dessa forma, todas foram abordadas e convidadas a participar do estudo, embora nem todas tenham se mostrado receptivas e/ ou aceitaram o convite. É importante destacar que, devido às características do local e para preservarem sua segurança, as pesquisadoras nunca compareciam sozinhas à penitenciária; estavam sempre em dupla ou trio.

As mulheres que aceitaram o convite, foram inicialmente questionadas em relação a preferência em serem entrevistadas ou de responderem individualmente o questionário. Uma vez que todas optaram em responder individualmente e percebeu-se que as mesmas possuíam escolaridade mínima para tanto, procedeu-se a entrega do questionário acompanhado do TCLE, acoplado em prancheta e caneta, com as orientaçóes referentes ao preenchimento. Essa ação foi realizada no pátio, no mesmo local em que as mulheres aguardavam o horário da visita, pois, além de não existir um local privativo, não era possível interferir no serviço e na rotina estabelecida pelas próprias participantes do estudo, que voluntariamente organizavam-se em filas por ordem de chegada e enquanto esperavam, conversavam entre si e em pequenos grupos e também se arrumavam/preparavam para a visita (maquiagem, cabelo, unhas, sobrancelhas, manicure e troca de roupa). Quando precisavam sair para tomar café ou usar o banheiro em estabelecimentos comerciais (bares) na frente da penitenciária, deixavam suas sacolas guardando a fila, o que era respeitado por todas. As pesquisadoras ficavam próximas e se colocavam à disposição para esclarecer quaisquer dúvidas que pudessem surgir. $\mathrm{O}$ tempo médio de preenchimento do questionário foi de 15 minutos. No total, foram realizadas 19 visitas à penitenciária, sendo encerradas quando se identificou que, nas últimas cinco, apenas uma ou duas novas participantes foram incluídas no estudo.

O instrumento utilizado na coleta de dados foi um questionário autoaplicável estruturado, constituído de duas partes. A primeira compunha-se de questôes que abordavam características sociodemográficas das participantes e de seus companheiros; a segunda, uma adaptação do checklist de avaliação de risco de violência contra parceira íntima, construído e validado no Brasil, constituído por 100 questóes. ${ }^{(14)}$

A adaptação realizada refere-se apenas à exclusão de questóes, pois o questionário original destinava-se às mulheres que sabidamente eram vítimas de violência pelo parceiro íntimo, e no presente estudo ainda era necessário identificar a prevalência desse tipo de evento entre mulheres de apenados e náo avaliar o risco de novos episódios. Dessa forma, o questionário utilizado foi constituído de 50 questôes, com respostas sim /não, distribuídas em 16 dimensôes, a saber: Perfil do autor da violência e da vítima; Conflitos interpessoais; Uso de álcool e/ou de drogas; Percepção sobre a violência; Experiências de violência na família de origem; Situação ocupacional; Saúde mental do parceiro; Saúde mental da mulher; Filhos de outra relação íntima; Outras violências; História de violência contra a parceira; 
Violência contra a parceira na presença de outros; Separação/divórcio; Rede social; Meios de agressão; e Rede de atenção. Ademais, considerou-se inconveniente submeter as participantes a questionamentos que, além de não se coadunarem ao objetivo do estudo, poderiam expô-las demasiadamente a situaçôes de constrangimento ou de sobrecarga emocional decorrente de lembranças negativas.

As variáveis independentes analisadas foram aquelas que possibilitaram a identificação de características sociodemográficas das mulheres, entre as quais: Faixa etária (menos de 35 anos / 35 anos ou mais); Cor da pele (branca / não branca); Trabalha fora ( $\operatorname{sim} /$ não); Tempo de estudo (mais de oito anos / até oito anos); Dependência química ( $\operatorname{sim} /$ não); Tem religião (sim / não); Estado Civil (solteira / casada ou união estável); Parceiros no passado (sim / não); Filhos com parceiro atual (sim / não); Filhos de outro relacionamento (sim / não); Recebimento de Benefício social (sim / não); Renda (mais de um salário / até um salário). Ao final do Check-list foi acrescentada a questão - Você já foi vítima de alguma forma de violência por parte deste seu companheiro que está preso? ( $\operatorname{sim} /$ não).

O recorte da análise contou com múltiplas variáveis dependentes com categorização dicotômica ( 0 = não / $1=\operatorname{sim})$, pois se considerou como interesse as respostas afirmativas às questóes de número 1 a 48 do Checklist. Para a confecção do banco de dados, utilizou-se o software Microsoft Excel 2016. As análises foram realizadas por meio do pacote estatístico SPSS (versão 20). Os dados foram submetidos inicialmente à análise descritiva, com a geração de tabelas de contingência para realização do teste de associação de qui-quadrado.

Posteriormente, passou-se à abordagem dos dados sob a ótica de modelos de regressão de Poisson, de modo que a primeira etapa constituiu-se de análise bruta (bivariada), em que cada variável independente foi relacionada com as variáveis dependentes, de modo a se realizar a seleção das variáveis que seriam inseridas na análise multivariável (ajustada). Para tal seleção, considerou-se como critério o valor de $\mathrm{p}<0,25$, permitindo inclusão de um maior número de variáveis no modelo.

Em seguida, passou-se à inserção em bloco das variáveis independentes que atenderam ao critério ado- tado, de modo que cada modelo final correspondente a cada variável dependente incluísse aquelas com valor de $\mathrm{p}<0,25$ na análise bruta e foram mantidos aqueles modelos que apresentavam ao menos uma variável associada significativamente, tomando-se como referência para tal significância o valor de $\mathrm{p}<0,05$. Como teste de hipóteses, adotou-se o qui-quadrado de Wald.

No desenvolvimento do estudo foram seguidas normas nacionais e internacionais de pesquisa com seres humanos e o projeto foi aprovado pelo Comitê da Universidade Estadual de Maringá (Parecer: 2.566.858). Destaca-se que após a coleta dos dados, um panfleto contendo a relação dos dispositivos que compóem a rede de enfrentamento à violência contra a mulher no município, foi entregue a todas as participantes, independentemente de as mesmas terem ou não relatado violência por parceiro íntimo. O objetivo desta ação foi disseminar informaçóes sobre as possibilidades de ajuda e de acesso à rede de serviços existentes.

\section{Resultados}

Dentre as 136 mulheres participantes, a maioria $(63,9 \%)$ tinha idade entre 20 e 29 anos e declararam-se casadas ou em união estável $(88,2 \%)$, sendo que $50,7 \%$ eram de cor náo branca, $44,1 \%$ tinham até oito anos de estudo e 55,8\% mais de oito anos. Do total de participantes, $49,2 \%$ declararam-se católicas e 43,3\% afirmaram ser dependentes ou fazer uso de substâncias psicoativas. Mais da metade trabalhava $(57,3 \%)$, a maioria afirmou ter tido parceiros anteriores $(83,7 \%), 54,3 \%$ referiu tempo de relacionamento com o parceiro apenado entre um e cinco anos, e 65\% disse ter filhos com ele. Não houve relatos de prisão do parceiro por violência conjugal. Cabe destacar que os casos considerados no presente estudo foram somente aqueles em que os parceiros atuais praticaram violência, independente de que os parceiros anteriores a tenham efetuado.

$\mathrm{Na}$ análise ajustada, o estado civil manteve-se associado ao uso de álcool e outras drogas pelo parceiro nos últimos incidentes de violência $(\mathrm{p}=0,009)$, de modo que a prevalência de mulheres que referiram o uso de substância pelo parceiro foi 0,42 vezes a pre- 
valência observada entre as que negaram. Verificou-se associação da dependência química com a sensação de tristeza e falta de prazer para fazer coisas que antes eram prazerosas $(\mathrm{p}=0,029)$ (Tabela 1$)$.

O estado civil apresentou significância estatística com a ameaça "se eu não posso ter você, ninguém mais pode" $(\mathrm{p}=0,026)$. Dessa forma, a prevalência de mulheres que disseram que o companheiro já as ameaçou foi 0,59 vezes a prevalência das que negaram tal atitude do parceiro. Ou seja, a associação negativa observada $(\mathrm{RP}<1)$ indica menor preva- lência de mulheres com companheiro entre as que responderam positivamente em comparação às que negaram a ameaça (Tabela 1 ).

A análise ajustada apresentada na tabela 2 demonstrou que o estado civil se manteve associado à identificação de pessoas (familiares, colegas de trabalho/escola, amigos ou da comunidade) com quem pode contar nos momentos difíceis $(\mathrm{p}=0,016)$, e a frequência de mulheres com companheiro foi menor entre as que responderam positivamente do que entre aquelas que negaram ter o apoio de outras pes-

Tabela 1. Razão de Prevalência (RP) bruta e multivariável (ajustada) para variáveis independentes em relação às questões sobre uso de drogas, aspectos emocionais e de ameaça na avaliação de risco de violência em mulheres

\begin{tabular}{|c|c|c|c|c|c|c|}
\hline \multirow{2}{*}{ Variáveis } & \multicolumn{2}{|c|}{ Prevalência } & \multicolumn{2}{|c|}{ Análise bruta } & \multicolumn{2}{|c|}{ Análise multivariável (ajustada) } \\
\hline & $\operatorname{Sim}(\%)$ & Não (\%) & RP (IC95\%) & Wald ( $p$-value) & RP (IC95\%) & Wald ( $p$-value) \\
\hline \multicolumn{7}{|c|}{ Q7. Ele estava usando álcool ou drogas durante os últimos incidentes de violência? } \\
\hline \multicolumn{7}{|l|}{ Estado civil } \\
\hline Casada/união estável & 78,1 & 91,3 & $\begin{array}{c}0,44 \\
(0,23-0,84)\end{array}$ & $\begin{array}{c}6,181 \\
(0,013)\end{array}$ & $\begin{array}{c}0,42 \\
(0,22-0,80)\end{array}$ & $\begin{array}{c}6,883 \\
(0,009)\end{array}$ \\
\hline Solteira & 21,9 & 8,7 & 1 & & 1 & \\
\hline \multicolumn{7}{|l|}{ Filhos com Parceiro atual } \\
\hline Sim & 77,4 & 61,2 & $\begin{array}{c}1,89 \\
(0,88-4,06)\end{array}$ & $\begin{array}{c}2,701 \\
(0,100)\end{array}$ & $\begin{array}{c}1,70 \\
(0,78-3,70)\end{array}$ & $\begin{array}{c}1,802 \\
(0,179)\end{array}$ \\
\hline Não & 22,6 & 38,8 & 1 & & & \\
\hline \multicolumn{7}{|c|}{ Filhos de outro relacionamento } \\
\hline Sim & 37,5 & 50,5 & $\begin{array}{c}0,62 \\
(0,32-1,19)\end{array}$ & $\begin{array}{l}2,055 \\
(0,152)\end{array}$ & $\begin{array}{c}0,63 \\
(0,33-1,21)\end{array}$ & $\begin{array}{l}1,870 \\
(0,171)\end{array}$ \\
\hline Não & 62,5 & 49,5 & 1 & & & \\
\hline \multicolumn{7}{|c|}{ Q18.Você se sente triste na maior parte do tempo e sem prazer em fazer coisas que antes eram prazerosas? } \\
\hline \multicolumn{7}{|l|}{ Faixa etária } \\
\hline 35 anos ou mais & 22,1 & 10,3 & $\begin{array}{c}1,37 \\
(0,94-2,00)\end{array}$ & $\begin{array}{l}2,733 \\
(0,098)\end{array}$ & $\begin{array}{c}1,29 \\
(0,86-1,95)\end{array}$ & $\begin{array}{c}1,512 \\
(0,219)\end{array}$ \\
\hline Menos de 35 anos & 77,9 & 89,7 & 1 & & 1 & \\
\hline \multicolumn{7}{|l|}{ Dependência química } \\
\hline $\operatorname{Sim}$ & 52,9 & 33,8 & $\begin{array}{c}1,48 \\
(1,06-2,08)\end{array}$ & $\begin{array}{l}5,230 \\
(0,022)\end{array}$ & $\begin{array}{c}1,45 \\
(1,04-2,02)\end{array}$ & $\begin{array}{c}4,761 \\
(0,029)\end{array}$ \\
\hline Não & 47,1 & 66,2 & 1 & & 1 & \\
\hline \multicolumn{7}{|l|}{ Benefício } \\
\hline Sim & 32,4 & 44,1 & 1 & & 1 & \\
\hline Não & 67,6 & 55,9 & $\begin{array}{c}1,30 \\
(0,89-1,91)\end{array}$ & $\begin{array}{l}1,900 \\
(0,168)\end{array}$ & $\begin{array}{c}1,24 \\
(0,86-1,79)\end{array}$ & $\begin{array}{l}1,327 \\
(0,249)\end{array}$ \\
\hline \multicolumn{7}{|l|}{ Renda } \\
\hline Até 1 salário & 36,8 & 51,5 & $\begin{array}{c}0,73 \\
(0,51-1,05)\end{array}$ & $\begin{array}{l}2,884 \\
(0,089)\end{array}$ & $\begin{array}{c}0,75 \\
(0,53-1,06)\end{array}$ & $\begin{array}{c}2,534 \\
(0,111)\end{array}$ \\
\hline Mais de 1 salário & 63,2 & 48,5 & 1 & & 1 & \\
\hline \multicolumn{7}{|c|}{ Q27. Ele já ameaçou você dizendo algo parecido com a frase "se eu não posso ter você, ninguém mais pode"? } \\
\hline \multicolumn{7}{|l|}{ Trabalha fora } \\
\hline Sim & 50,0 & 37,3 & $\begin{array}{c}1,34 \\
(0,87-2,06)\end{array}$ & $\begin{array}{l}1,749 \\
(0,186)\end{array}$ & $\begin{array}{c}1,37 \\
(0,90-2,10)\end{array}$ & $\begin{array}{l}2,201 \\
(0,138)\end{array}$ \\
\hline Não & 50,0 & 62,7 & 1 & & 1 & \\
\hline \multicolumn{7}{|l|}{ Estado civil } \\
\hline Casada/união estável & 82,7 & 91,6 & $\begin{array}{c}0,59 \\
(0,36-0,95)\end{array}$ & $\begin{array}{l}4,651 \\
(0,031)\end{array}$ & $\begin{array}{c}0,59 \\
(0,37-0,94)\end{array}$ & $\begin{array}{c}4,926 \\
(0,026)\end{array}$ \\
\hline Solteira & 17,3 & 8,4 & 1 & & 1 & \\
\hline \multicolumn{7}{|l|}{ Filhos de parceiro atual } \\
\hline $\operatorname{Sim}$ & 72,0 & 60,2 & $\begin{array}{c}1,44 \\
(0,87-2,38)\end{array}$ & $\begin{array}{c}2,004 \\
(0,157)\end{array}$ & $\begin{array}{c}1,45 \\
(0,88-2,39)\end{array}$ & $\begin{array}{l}2,190 \\
(0,139)\end{array}$ \\
\hline Não & 28,0 & 39,8 & 1 & & 1 & \\
\hline
\end{tabular}


Tabela 2. Razão de Prevalência (RP) bruta e multivariável (ajustada) para variáveis independentes em relação às questões sobre suporte social e de saúde na avaliação de risco de violência em mulheres

\begin{tabular}{|c|c|c|c|c|c|c|}
\hline \multirow{2}{*}{ Variáveis } & \multicolumn{2}{|c|}{ Prevalência } & \multicolumn{2}{|c|}{ Análise bruta } & \multicolumn{2}{|c|}{ Análise multivariável (ajustada) } \\
\hline & $\operatorname{Sim}(\%)$ & Não (\%) & $\mathrm{RP}(\mathrm{IC} 95 \%)$ & Wald ( $p$-value) & RP (IC95\%) & Wald ( $p$-value) \\
\hline \multicolumn{7}{|c|}{ Q40. Você possui pessoas com quem pode contar nos momentos difíceis? } \\
\hline \multicolumn{7}{|l|}{ Trabalha fora } \\
\hline Sim & 38,2 & 54,5 & $\begin{array}{c}0,85 \\
(0,68-1,05)\end{array}$ & $\begin{array}{l}2,298 \\
(0,130)\end{array}$ & $\begin{array}{c}0,83 \\
(0,68-1,03)\end{array}$ & $\begin{array}{l}2,803 \\
(0,094)\end{array}$ \\
\hline Não & 61,8 & 45,5 & 1 & & 1 & \\
\hline \multicolumn{7}{|l|}{ Estado civil } \\
\hline Casada/união estável & 85,3 & 97,0 & $\begin{array}{c}0,77 \\
(0,65-0,92)\end{array}$ & $\begin{array}{l}8,005 \\
(0,005)\end{array}$ & $\begin{array}{c}0,79 \\
(0,66-0,96)\end{array}$ & $\begin{array}{l}5,796 \\
(0,016)\end{array}$ \\
\hline Solteira & 14,7 & 3,0 & 1 & & 1 & \\
\hline \multicolumn{7}{|c|}{ Filhos de outros relacionamentos } \\
\hline Sim & 50,5 & 36,4 & $\begin{array}{c}1,15 \\
(0,94-1,40)\end{array}$ & $\begin{array}{c}1,868 \\
(0,172)\end{array}$ & $\begin{array}{c}1,15 \\
(0,94-1,41)\end{array}$ & $\begin{array}{l}1,997 \\
(0,158)\end{array}$ \\
\hline Não & 49,5 & 63,6 & 1 & & 1 & \\
\hline \multicolumn{7}{|c|}{ Q41. Você gostaria de ter contato com amigos ou familiares, mas se sente impedida pelo seu parceiro? } \\
\hline \multicolumn{7}{|l|}{ Trabalha fora } \\
\hline Sim & 48,7 & 39,6 & $\begin{array}{c}1,41 \\
(0,82-2,43)\end{array}$ & $\begin{array}{c}1,557 \\
(0,212)\end{array}$ & $\begin{array}{c}1,51 \\
(0,90-2,55)\end{array}$ & $\begin{array}{l}2,465 \\
(0,116)\end{array}$ \\
\hline Não & 60,4 & 51,3 & 1 & & 1 & \\
\hline \multicolumn{7}{|l|}{ Estado Civil } \\
\hline Casada/união estável & 76,9 & 92,7 & $\begin{array}{c}0,47 \\
(0,26-0,83)\end{array}$ & $\begin{array}{c}6,819 \\
(0,009)\end{array}$ & $\begin{array}{c}0,51 \\
(0,29-0,89)\end{array}$ & $\begin{array}{c}5,625 \\
(0,018)\end{array}$ \\
\hline Solteira & 23,1 & 7,3 & 1 & & 1 & \\
\hline \multicolumn{7}{|l|}{ Vícios } \\
\hline Sim & 53,8 & 39,6 & $\begin{array}{c}1,52 \\
(0,88-2,63)\end{array}$ & $\begin{array}{l}2,307 \\
(0,129)\end{array}$ & $\begin{array}{c}1,31 \\
(0,73-2,35)\end{array}$ & $\begin{array}{c}0,825 \\
(0,364)\end{array}$ \\
\hline Não & 46,2 & 60,4 & 1 & & 1 & \\
\hline \multicolumn{7}{|l|}{ Tem religião } \\
\hline $\operatorname{Sim}$ & 92,3 & 99,0 & 1 & & 1 & \\
\hline Não & 7,7 & 1,0 & $\begin{array}{c}2,80 \\
(1,48-5,28)\end{array}$ & $\begin{array}{l}10,119 \\
(0,001)\end{array}$ & $\begin{array}{c}2,20 \\
(1,18-4,12)\end{array}$ & $\begin{array}{l}6,210 \\
(0,013)\end{array}$ \\
\hline \multicolumn{7}{|l|}{ Renda } \\
\hline Até 1 salário & 51,3 & 41,7 & $\begin{array}{c}1,39 \\
(0,80-2,40)\end{array}$ & $\begin{array}{c}1,402 \\
(0,236)\end{array}$ & $\begin{array}{c}1,45 \\
(0,86-2,46)\end{array}$ & $\begin{array}{c}1,976 \\
(0,160)\end{array}$ \\
\hline Mais de 1 salário & 48,7 & 58,3 & 1 & & 1 & \\
\hline \multicolumn{7}{|c|}{ Q42. Ele tenta evitar que você veja médicos, psicólogos ou outros profissionais de saúde? } \\
\hline \multicolumn{7}{|l|}{ Estado civil } \\
\hline Com companheiro & 80,0 & 90,0 & $\begin{array}{c}0,51 \\
(0,23-1,17)\end{array}$ & $\begin{array}{l}2,488 \\
(0,115)\end{array}$ & $\begin{array}{c}0,53 \\
(0,23-1,23)\end{array}$ & $\begin{array}{l}2,153 \\
(0,142)\end{array}$ \\
\hline Sem companheiro & 20,0 & 10,0 & 1 & & 1 & \\
\hline \multicolumn{7}{|l|}{ Tem religião } \\
\hline $\operatorname{Sim}$ & 92,0 & 98,2 & 1 & & 1 & \\
\hline Não & 8,0 & 1,8 & $\begin{array}{c}2,76 \\
(0,97-7,87)\end{array}$ & $\begin{array}{l}3,611 \\
(0,057\end{array}$ & $\begin{array}{c}2,96 \\
(1,10-7,96)\end{array}$ & $\begin{array}{c}4,626 \\
(0,031)\end{array}$ \\
\hline \multicolumn{7}{|l|}{ Parceiros passados } \\
\hline Sim & 72,0 & 86,2 & $\begin{array}{c}0,52 \\
(0,24-1,09)\end{array}$ & $\begin{array}{c}2,992 \\
(0,084)\end{array}$ & $\begin{array}{c}0,47 \\
(0,21-1,02)\end{array}$ & $\begin{array}{l}3,617 \\
(0,057)\end{array}$ \\
\hline Não & 28,0 & 13,8 & 1 & & 1 & \\
\hline \multicolumn{7}{|c|}{ Q48. Você já precisou procurar um serviço de saúde por conta da violência? } \\
\hline \multicolumn{7}{|l|}{ Estado civil } \\
\hline Casada/união estável & 79,5 & 91,7 & $\begin{array}{c}0,50 \\
(0,28-0,88)\end{array}$ & $\begin{array}{l}5,825 \\
(0,016)\end{array}$ & $\begin{array}{c}0,54 \\
(0,32-0,92)\end{array}$ & $\begin{array}{c}5,082 \\
(0,024)\end{array}$ \\
\hline Solteira & 20,5 & 8,3 & 1 & & 1 & \\
\hline \multicolumn{7}{|l|}{ Filhos com parceiro atual } \\
\hline Sim & 76,9 & 59,6 & $\begin{array}{c}1,86 \\
(0,97-3,58)\end{array}$ & $\begin{array}{c}3,492 \\
(0,062)\end{array}$ & $\begin{array}{c}2,03 \\
(1,06-3,89)\end{array}$ & $\begin{array}{c}4,578 \\
(0,032)\end{array}$ \\
\hline Não & 23,1 & 40,4 & 1 & & 1 & \\
\hline \multicolumn{7}{|c|}{ Filhos de outro relacionamento } \\
\hline Sim & 56,4 & 43,2 & $\begin{array}{c}1,48 \\
(0,87-2,52)\end{array}$ & $\begin{array}{l}2,125 \\
(0,145)\end{array}$ & $\begin{array}{c}1,60 \\
(0,94-2,70)\end{array}$ & $\begin{array}{l}3,043 \\
(0,081)\end{array}$ \\
\hline Não & 43,6 & 56,8 & 1 & & 1 & \\
\hline
\end{tabular}


soas. O estado civil também foi associado ao desejo de ter contato com outras pessoas, mas sentir-se impedidas pelo parceiro $(\mathrm{p}=0,018)$ e à procura do serviço de saúde por conta da violência $(p=0,024)$, pois, a prevalência de mulheres casadas entre as que responderam positivamente essas questôes foi, respectivamente, de 0,51 e de 0,54 vezes a prevalência observada entre as que responderam negativamente.

A variável "Religião" foi associada positivamente $(\mathrm{RP}>1)$ ao desejo de ter contatos com amigos e familiares, mas sentir-se impedida pelo parceiro $(\mathrm{p}=0,013)$ e à atitude do parceiro de impedir que a mulher tivesse contato com médicos, psicólogos e outros profissionais de saúde $(\mathrm{p}=0,031)$, de modo que a frequência de mulheres que não aderiam à alguma religiáo foi maior entre as que responderam positivamente as referidas questóes, com $\mathrm{RP}=2,20$ e $R P=2,96$, respectivamente.

Além disso, observou-se também associação positiva da variável "Filhos com parceiro atual" com a atitude do parceiro de evitar que a mulher tivesse contato com médicos, psicólogos e outros profissionais de saúde $(p=0,032)$, sendo que a frequência de mulheres que tinham filhos com o parceiro atual foi significativamente maior entre as que percebiam uma postura restritiva do parceiro do que entre as que negaram essa postura, com $R P=2,03$.

\section{Discussão}

Os resultados deste estudo evidenciaram elevado consumo de álcool e outras drogas pelo parceiro nos episódios de violência, o que vulnerabiliza ainda mais as mulheres a essas situações nas relações conjugais. ${ }^{(1)}$ No Marrocos, estudo realizado com 254 mulheres vítimas de violência conjugal, evidenciou que, em $82 \%$ dos casos ocorridos, os agressores estavam sob efeito de drogas ou álcool. ${ }^{(15)}$ Do mesmo modo, estudo realizado na Arábia Saudita, com 497 mulheres, apontou como preditor da violência a dependência de álcool e drogas pelo parceiro. ${ }^{(16)}$

A concomitância do uso de substâncias químicas entre o parceiro e a mulher, também observada no presente estudo, pode ser influenciada pelo contexto de criminalidade no qual estão inseridos. Sob esse aspecto, pesquisa realizada em Florianópolis/ Santa Catarina, com mulheres vítimas de violência conjugal, asseverou que o consumo de álcool e outras drogas por elas, pode estar relacionado a uma tentativa de "automedicar" a dor e o mal-estar oriundos da convivência com situaçóes violentas e traumáticas. ${ }^{(17)}$ Diante disso, reitera-se a importância de investigar o uso do álcool e outras drogas em mulheres, pois este uso pode constituir indicativo da presença de violência.

Destaca-se, neste estudo, associação significativa entre violência conjugal e a sensação de tristeza e falta de prazer em fazer coisas que antes eram prazerosas. Estudo realizado com 375 mulheres vítimas de violência conjugal na Grécia concluiu que os relacionamentos violentos apresentaram associação com problemas de ordem física, mas principalmente com sintomas depressivos. ${ }^{(18)}$ Do mesmo modo, estudo desenvolvido com mulheres vítimas de violência conjugal nos Estados Unidos constatou relatos de ideaçáo suicida por $42 \%$ delas, sendo que $31 \%$ revelou já ter tentado suicídio em algum momento da vida. Além disso, 34\% fazia uso regular de vários psicotrópicos e apresentava sentimentos de medo, estresse, tristeza e depressão. ${ }^{(19)}$

O fato de 53,7\% das mulheres assinalarem não conseguir imaginar a vida sem o parceiro chamou a atenção, pois isso demonstra certa dependência, que pode ser de caráter afetivo, financeiro ou protetivo. Estudo que buscou analisar o discurso da dependência afetiva de mulheres em condição de violência conjugal apontou que a mulher pode permanecer submissa ao agressor por motivaçóes de cunho emocional, como pensamentos/comportamentos de inferioridade, ultrapassando seu próprio bem-estar, de modo que, mesmo diante da violência conjugal, ela pode silenciar, com receio de romper a relação. ${ }^{(20)}$

Outro resultado que chama a atenção diz respeito à presença de ameaças, pois estas podem refletir negativamente na saúde mental da vítima. Investigação desenvolvida com 613 chinesas apontou, em seus resultados, que, dentre as formas de violência, as açôes controladoras, entre as quais as ameaças, foram as que mais geraram consequências negativas à saúde mental das vítimas, desencadean- 
do a necessidade de utilização frequente de serviços médicos por sintomas de depressão e distúrbio de estresse pós-traumático. ${ }^{(21)}$

Observou-se, no presente estudo, que até mesmo as mulheres que se declararam solteiras, mas mantinham relaçóes de intimidade, estavam expostas a práticas violentas. Isso porque a frequência destas foi maior entre as que confirmaram ter sofrido ameaças restritivas do que entre as que negaram sofrê-las. Esse resultado corrobora estudo realizado com 245 mulheres residentes em uma comunidade de Recife/Pernambuco, o qual apontou que a frequência de mulheres que confirmaram ter sofrido violência foi significativamente maior entre as que negaram ter companheiro $(51,8 \%)$ do que entre as que tinham companheiro $(27,8 \%) .{ }^{(3)}$ Acredita-se que esse fato pode estar relacionado ao receio que possuem em expor seus relacionamentos e, consequentemente, o agressor, pois observou-se, no presente estudo, que algumas mulheres que afirmaram serem solteiras assinalaram positivamente as questôes de violência praticadas contra elas; já aquelas que se declararam casadas, raramente assinalaram a presença de práticas de violência. Este resultado permite inferir que ao afirmar não possuir compromisso formal com o companheiro a quem visitava, a mulher sentia mais liberdade em expor as açóes violentas sofridas.

Outro fator destacado foi o de as mulheres sentirem-se impedidas pelo parceiro de manter contato com outras pessoas. Essas atitudes de controle e vigilância, com a intenção de mantê-las submissas, ou ainda pelo receio de que a situação de violência seja relatada, podem ser vivenciadas pelas mulheres como uma forma de cuidado recebido. ${ }^{(8)}$ Estudo realizado com mulheres que visitavam companheiros presos em uma penitenciária localizada no Rio Grande do Sul, apontou que muitas delas eram controladas fora da prisão por seus companheiros que estavam dentro da instituição, e que estes mantinham certo poder disciplinar sobre elas. ${ }^{(22)}$ É importante destacar que tais atos não são exclusivos de homens envolvidos com a criminalidade, pois estudo realizado no Espírito Santo, com mulheres cujos parceiros náo tinham quaisquer envolvimento com a justiça, revelou que eles tinham comportamentos de caráter controlador, com o objetivo de privar a liberdade, os relacionamentos interpessoais e os direitos de escolha das mulheres. ${ }^{(23)}$

Mesmo que o presente estudo tenha evidenciado importante relação entre violência e o fato de a mulher ter filhos com o agressor, na literatura não foram encontradas evidências que justifiquem este achado. Entretanto, estudo aponta que os filhos são uma das principais razóes para que muitas mulheres permaneçam no relacionamento violento ${ }^{(24)}$ ou, por outro lado, tomem a iniciativa de romper com o ciclo da violência e até mesmo denunciem o agressor. ${ }^{(25)}$

O impedimento de contato com amigos, familiares, ou profissionais de saúde, foi mais frequente entre as mulheres que mantinham um relacionamento estável e não seguiam alguma religião. Pesquisa que buscou compreender a rede social de mulheres violentadas em Sáo Paulo mostrou que a religião foi determinante para a decisão de buscar ajuda por algumas delas. ${ }^{(26)}$ No entanto, vale considerar que nem sempre a religião constitui um dispositivo primário de apoio às mulheres em situação de violência, já que, por vezes, pode reforçar os estereótipos de gênero e, consequentemente, influenciar na efemeridade de situaçóes de violência. Nesse sentido, há necessidade de investigar qual a influência que essa rede de apoio exerce, em especial por constituir um tipo de estereotipo variável e influenciado por contextos culturais. ${ }^{(27)}$

Estudos revelam que os familiares e amigos são a rede social primária da vítima e possuem maior potencial para ajudá-la a sair da situação de violência, enquanto que a procura por ajuda médica e religiosa, polícia, serviços de saúde e judiciais se revela como rede social secundária. ${ }^{(24-28)} \mathrm{O}$ comportamento do companheiro, portanto, limita as redes sociais que poderiam ofertar suporte e o apoio necessário à mulher e, consequentemente, o reconhecimento e enfrentamento da situação. ${ }^{(26)}$

No que tange à procura do serviço de saúde em razão da violência sofrida, 79,5\% das mulheres casadas e $20,5 \%$ das solteiras referiram já ter procurado algum serviço, embora tenham continuado o relacionamento com o agressor. Apesar de a violência conjugal estar cotidianamente presente nos serviços de saúde, o desconhecimento dos profissionais sobre 
o problema e seu enfrentamento também pode ser um fator contribuinte para que o agravo permaneça na esfera privada. Isto por que, ao procurar auxílio nos serviços de saúde, muitas vezes, as mulheres que vivenciam violência conjugal não são acolhidas de modo a sentirem-se seguras, além de, às vezes, terem suas queixas questionadas. ${ }^{(29)} \mathrm{Ou}$ seja, até mesmo nesses locais existe um processo sutil de reprodução das desigualdades de gênero ao se colocar em prática as políticas voltadas para o atendimento às mulheres em situação de violência. ${ }^{(26)}$

No caso das mulheres de apenados, esta parcela da população, apesar de significativa, procura menos os serviços de saúde, e quando o faz não expóe verdadeiramente suas necessidades devido ao estereótipo de mulher de companheiro envolvido na criminalidade que muitas vezes carregam. ${ }^{(8)}$ Além disso, é muito difícil para essas mulheres citarem a violência conjugal como queixa principal ao buscarem ajuda, seja por vergonha, medo ou dificuldade em se expor. Atinente a esse fato, o atendimento de saúde ainda é voltado para as queixas explícitas, e essa visão está enraizada tanto nos usuários quanto nos profissionais de saúde. ${ }^{(30)}$

A partir do exposto, considera-se que a dificuldade de as vítimas de violência conjugal exporem as questóes mais íntimas de afeto, muitas vezes concorre para o desconhecimento da gravidade da situação. Por isso, no que se refere a mulheres de apenados, é importante conhecer o cotidiano dessa população, seus saberes e experiências, para que se possa abrir possibilidades e ampliar ações em prol de suas necessidades. Isto pode potencializar novas investigaçóes e estratégias no campo da atenção à saúde. ${ }^{(11)}$

Nesse contexto, a atuaçáo do enfermeiro deve visar a promoção de um cuidado integral à mulher, com ênfase na qualidade de vida, e que ela possa ver nos serviços, em especial na atenção primária - porta de entrada no sistema de saúde -, um local de acolhimento, que lhe permita participar do planejamento de estratégias de enfrentamento, sem causar-lhe danos ainda maiores e aos seus filhos. Ressalta-se que o acolhimento a essas mulheres necessita ser diferenciado, pois a relação de confiança possibilita que os profissionais reconheçam fatores de risco, condiçóes de vulnerabilidades e planejem ações de cuidado específicas.

No entanto, cabe destacar que, às vezes, essas mulheres não buscam espontaneamente a rede de apoio, o que torna necessária a busca ativa e a constante vigilância da equipe de saúde na identificação precoce de fatores de risco. Para tanto, torna-se necessário o estabelecimento de parcerias entre o setor saúde e prisional, a fim de que ocorra o planejamento e a implementação de ações compartilhadas. Esta parceria pode ser operacionalizada por meio de açôes de educação em saúde com enfoque no autocuidado e considerando as condiçôes psicológicas destas mulheres, de modo a favorecer uma maior aproximação às especificidades desse público.

Além disso, um dos passos mais importantes para o enfrentamento da violência conjugal, e que se estende para além da população em estudo, é o estímulo ao empoderamento das mulheres, de modo que estas consigam identificar situaçóes de violência e se percebam como vítimas, para então buscarem autonomia e independência e, consequentemente, terem condiçóes de romper com o relacionamento abusivo e exigir seus direitos. Entretanto, apesar de alguns avanços alcançados ao longo dos anos, estas açôes ainda representam um desafio à sociedade atual.

Destacam-se como limitaçôes desta pesquisa, o fato de ter sido realizada em um único município, à ausência de investigação do risco para ocorrência de novas situaçôes de violência e ainda, à seleção não probabilística da amostra, visto a dificuldade de conhecer o número real de mulheres que realizavam as visitas, a frequência com que as faziam, assim como a dificuldade de abordar esta população. Ademais, considera-se que o fato de a coleta dos dados ter ocorrido na penitenciária, enquanto aguardavam o horário de visita ao parceiro, pode ter, em parte, despertado sentimento de medo e inibido as mulheres de responderem fidedignamente as questóes do instrumento.

De qualquer modo, os resultados encontrados são válidos, considerando-se as dificuldades em se estudar a violência conjugal, especialmente entre mulheres de apenados. Estas mulheres precisam ter maior visibilidade na sociedade e os resultados desta pesquisa reforçam isto, especialmente a importância 
de se identificar os fatores associados à esta problemática. Primeiro por que a violência conjugal tende a se intensificar ao longo do tempo e, depois, porque conhecer esses fatores poderá alertar sobre o que pode ser modificado para diminuir o número alarmante de casos de violência e suas consequências.

Por fim, os resultados fornecem subsídios para à prática dos profissionais de saúde, em especial para aqueles atuantes na atenção primária, que ao reconhecerem os fatores associados à ocorrência de violência conjugal, podem estabelecer comportamentos e atitudes mais sensíveis e, a partir disto, promover a inclusão, o diálogo e o vínculo, considerando a vulnerabilidade destas mulheres. Assim, recomenda-se a realização de estudos em diferentes cenários, de modo a contribuir para a ampliação de evidências científicas e discussôes acerca dessa temática.

\section{Conclusão}

Os fatores associados à ocorrência de violência conjugal em mulheres de apenados foram: uso de substâncias químicas tanto pela mulher quanto pelo parceiro, estado civil solteira, ausência de religião e presença de filhos com o parceiro. Os tipos mais frequentes foram: ameaças, impedimento da procura de serviços de saúde e de contato com a família, amigos e/ou comunidade. $\mathrm{O}$ uso de substâncias químicas por elas e por seus parceiros, inclusive nos episódios de violência ocorridos, desencadearam sentimentos de tristeza e ausência de prazer em fazer coisas antes prazerosas. Vale salientar que a simples identificação dos fatores sociodemográficos das vítimas não é suficiente para elaborar medidas para prevenção e o enfrentamento da violência conjugal entre as mulheres de apenados. No entanto, acredita-se que estas características configuram-se como importantes subsídios para identificação de perfis mais vulneráveis à ocorrência, o que, por conseguinte, pode favorecer a busca ativa de possíveis casos de violência na comunidade. Por outro lado, o desconhecimento sobre os fatores relacionados a essas práticas, impossibilita saber, por exemplo, onde, como, com quem e em que momento é possível fazer uso de medidas e estratégias de prevenção e enfrentamento da violência.

\section{Agradecimentos}

Á Coordenação de Aperfeiçoamento de Pessoal de Nível Superior - Brasil (CAPES).

\section{Colaborações}

Batista VC, Marcon SS, Arruda GO, Teston EF, Monteschio LVC, Godoy FJ, Cardelli AAM e Silva ES contribuíram com a concepção do estudo, análise e interpretação dos dados, redação do artigo, revisão crítica relevante do conteúdo intelectual e aprovação da versão final a ser publicada.

\section{Referências}

1. Vieira LB, Cortes LF, Padoin SM, Souza IE, de Paula CC, Terra MG. [Abuse of alcohol and drugs and violence against women: experience reports]. Rev Bras Enferm. 2014;67(3):366-72. Portuguese

2. Martins LC, Silva EB, Costa MC, Colomé IC, Fontana DG, Jahn AC. Violência contra mulher: acolhimento na estratégia saúde da família. Cienc Cuid Saude. 2016;15(3):507-14.

3. de Barros ÉN, Silva MA, Falbo Neto GH, Lucena SG, Ponzo L, Pimentel AP. Prevalence and factors associated with intimate partner violence among women in Recife/Pernambuco, Brazil. Ciênc Saude Colet. 2016;21(2):591-8.

4. Organização Mundial da Saúde. [World Report on the Prevention of Violence 2014]. São Paulo: OMS, 2015. Portuguese.

5. Cerqueira D, Lima RS, Bueno S, Valencia LI, Hanashiro O, Machado PH, Lima AS. [Atlas of violence Ipea e FBSP]. Rio de Janeiro: Ipea; 2017. Portuguese.

6. Waiselfisz JJ. [Map of violence 2015: Homicide of women in Brazil]. Estud Av. 2007; 21(61):119-38. Portuguese.

7. Andrade RF, Araújo MA, Dourado MI, Miranda AB, Reis CB. [Prevalence of intimate partner violence and associated factors after disclosing the diagnosis of a sexually transmissible disease]. Cad Saude Publica. 2016;32(7):e00008715.

8. Federici JF, Humbelino TM, Santos IA. [Woman prisoner: expressions of gender violence]. II Seminário nacional de Serviço social, Trabalho e Políticas Sociais. Universidade Federal de Santa Catarina, Florianópolis, 2017. Portuguese.

9. Martins DC, Teston EF, Dobiesz BA, Fernandes CAM, Marcon SS. [Sexual and health behavior among women of convicts: an 43 exploratory study]. Online Braz J Nurs. 2019; 17(1):43-53. Portuguese.

10. Lima FS, Merchán-Hamann E, Urdaneta M, Damacena GN, Szwarcwald CL. Fatores associados à violência contra mulheres profissionais do sexo de dez cidades brasileiras. Cad Saude Publica. 2017;33(2):e00157815.

11. Martins DC, Pesce GB, Silva1 GM, Fernandes CA. [Sexual behavior and sexually transmitted diseases among the female partners of inmates]. Rev Lat Am Enfermagem. 2018;26:e3043. Portuguese. 
12. Lima CA, Deslandes SF. Violência sexual contra mulheres no Brasil: conquistas e desafios do setor saúde na década de 2000. Saude Soc. 2014;23(3):787-800

13. Batista VC. Violência por parceiro íntimo em mulheres de apenados. [dissertação]. Maringá: Universidade Estadual de Maringá; 2019.

14. Medeiros MN. Avaliação de Risco em Casos de Violência Contra a Mulher Perpetrada por Parceiro Íntimo [tese]. Brasília (DF): Instituto de Psicologia da Universidade de Brasília; 2015.

15. Boughima FA, Razine R, Benyaich $H$, Mrabet M. The profile of women victims of domestic violence in Morocco. Rev Med Leg. 2018;9(3):96102.

16. Alzahrani TA, Abaalkhail BA, Ramadan IK. Prevalence of intimate partner violence and its associated risk factors among Saudi female patients attending the primary healthcare centers in Western Saudi Arabia. Saudi Med J. 2016;37(1):96-9.

17. Martins VM, Bartilotti CB. "Acabou comigo como pessoa" A caracterização da violência doméstica a partir da percepção de mulheres violentadas. Cad Pesq. Interdisc Cienc Hum. 2015; 16(108): 41-61.

18. Watkins LE, Jaffe AE, Hoffman L, Gratz KL, Messman-Moore TL, DiLillo D. The longitudinal impact of intimate partner aggression and relationship status on women's physical health and depression symptoms. J Fam Psychol. 2014;28(5):655-65.

19. Karakurt G, Smith D, Whiting J. Impact of intimate partner violence on women's mental health. J Fam Violence. 2014;29(7):693-702.

20. Fabeni L, Souza LT, Lemos LB, Oliveira MC. The speech "love" and "affective dependence" on call to women in violence situation]. Rev NUFEN. 2016;7(1):32-47. Portuguese.

21. Tiwari AF, Fong DY, Wong JY. Effect of a purpose-built intervention for mental health of main land Chinese immigrant women who are survivors of intimate partner violence: a randomised controlled trial. Lancet. 2015; 386( S9):9. https://doi.org/10.1016/S01406736(15)00587-5

22. Cúnico SD, Strey MN, Costa AB. [Who is in charge? Bandit woman and the paradoxes of submission]. Rev Estud Fem. 2019;27(2):e54483. Portuguese.

23. Santos DF, Castro DS, Lima EFA, Neto LA, Moura MA, Leite FM. [The women's perception on the violence experienced]. Rev Pesqui Cuid Fundam. 2017; 9(1): 193-199. Portuguese.

24. Netto LA, Moura MA, Queiroz AB, Leite FM, Silva GF. [Isolation of women in situation of violence by intimate partner: a social network condition]. Esc Anna Nery. 2017;21(1):1-8. Portuguese.

25. Acosta DF, Gomes VL, Fonseca AD, Gomes GC. Violence against women commited by intimate partners: (in)visibility of the problem. Texto Contexto Enferm. 2015;24(1):121-7.

26. Dutra ML, Prates PL, Nakamura E, Villela WV. [The configuration of the social network of women living in domestic violence situations]. Ciênc Saúde Colet. 2013;18(5):1293-304. Portuguese.

27. Fiske ST. Prejudices in Cultural Contexts: Shared Stereotypes (Gender, Age) Versus Variable Stereotypes (Race, Ethnicity, Religion). Perspect Psychol Sci. 2017;12(5):791-9.

28. Krenkel S, Moré CL. Violência contra a mulher, casas-abrigo e redes sociais: revisão sistemática da literatura. Psicologia (Cons Fed Psicol). 2017;37(3):770-83

29. Williams JR, Halstead V, Salani D, Koermer N. An exploration of screening protocols for intimate partner violence in healthcare facilities: a qualitative study. J Clin Nurs. 2017;26(15-16):2192-201.

30. Rosa D0, Ramos RC, Gomes TM, Melo EM, Melo VH. Violência provocada pelo parceiro íntimo entre usuárias da Atenção Primária à Saúde: prevalência e fatores associados. Saúde Debate. 2018;42(4):67-80. 